\title{
SUBACUTE BACTERIAL ENDOCARDITIS WITH ONSET AS OPTIC NEURITIS
}

\author{
BY \\ RALPH KAUNTZE \\ From St. George's Hospital \\ Received January 20, 1947
}

Although retinitis, optic neuritis, or " choked disc" occurring in the course of subacute bacterial endocarditis is not uncommon (Kimmelstiel, 1928), complaint of visual abnormality or the finding or papillodema as an initial or early manifestation of the disease is not usual. The two following cases presented difficulty in diagnosis by the predominantly neurological picture, emphasized by involvement of the optic nerve.

\section{Case 1. Retrobular neuritis with subacute bacterial endocarditis.}

A housewife, aged 30 , was admitted to hospital with a story of increasingly misty vision in the right eye. At the age of 10 she had rheumatic fever and later during convalescence involvement of the aortic valve was noted. Since the birth of her first child by Caesarean section one year previously she had not felt completely well and had become easily fatigued, but there was no undue dyspnœa and she was able to swim and dance without inconvenience. One month before admission she noted black spots before the right eye followed by blurring of vision. There had not been limb weakness, diplopia, or abnormality in micturition.

Examination showed a well-built, somewhat obese young woman. There was a left internal rectus weakness (present since childhood) and blurring of the outline of the right optic disc. There was no gross defect of the visual fields on confrontation and the central nervous system otherwise showed no abnormality. There was a "collapsing " pulse, cardiac enlargement to the left with impulse four and three-quarter inches from the mid-line in the fifth left interspace, and aortic diastolic and systolic bruits. The blood pressure was 165/60. There were no signs of cardiac failure, except that the liver edge was palpable and tender one finger's breadth below the right costal margin. The cerebrospinal fluid at an initial pressure of $230 \mathrm{~mm}$. was otherwise normal. The Wassermann reaction in the blood and C.S.F. was negative. The blood sedimentation rate was $6 \mathrm{~mm}$. in the first hour. The urine was normal clinically and microscopically.

On X-ray screening there was enlargement of the left ventricle. An electrocardiogram showed splintering of R III, depression of S-T II, and inversion of T II and T III.

During one week in hospital there was no fever. The patient was discharged with a diagnosis of retrobulbar neuritis and rheumatic carditis (aortic reflux).

Eight months later she was again admitted to hospital. The amblyopia had disappeared within a month of her previous admission and for four months she had remained in fair health, until following a dental abscess she complained of headache, sweats, and increasing lassitude. There had been irregular fever, usually in the afternoon; nevertheless she continued at her household duties. For two days before admission she had noted painful spots in the palms of the hands.

Clinical examination showed a temperature of $101^{\circ} \mathrm{F}$., two Osler's nodes in the palm of the right hand, and two petechiæ over the right shin. There was no finger clubbing. Apart from tachycardia the cardiovascular signs (cardiac enlargement with aortic reflux) remained unchanged. The liver was no longer palpable but the spleen was now one finger's breadth 
below the costal margin. There was some pallor of the right optic disc and a small hæmorrhage in the right optic fundus; there were no other abnormal neurological findings.

Blood culture on three successive days grew Streptococcus viridans (penicillin sensitive). The red blood corpuscles were 4,100,000, the hæmoglobin 80 per cent, the white blood corpuscles were 9,600-polymorphs 73 per cent, lymphocytes 23 per cent, and mononuclears 4 per cent.

The urinary deposit showed red blood cells.

For the four days prior to treatment with penicillin the temperature was of the picket fence type. The fever responded to penicillin within twenty-four hours but during the first week of treatment a splenic infarct occurred and Osler's nodes appeared at intervals. In the

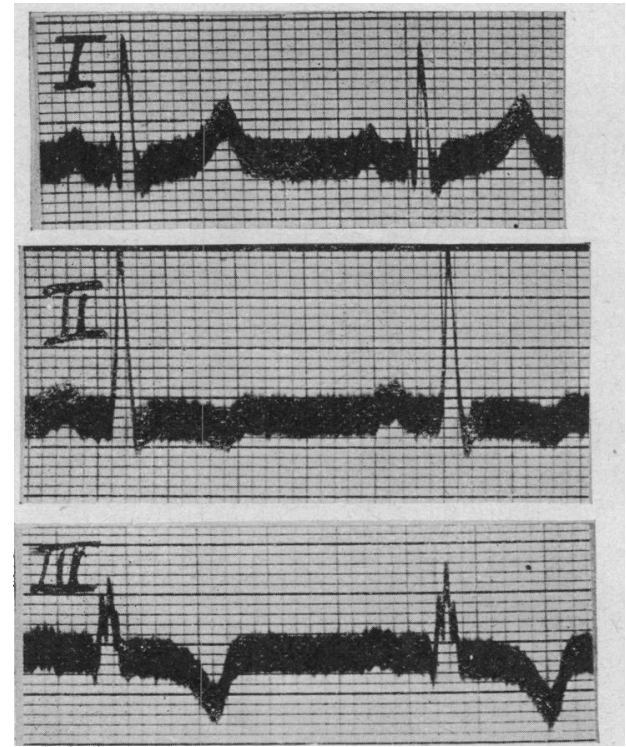

A

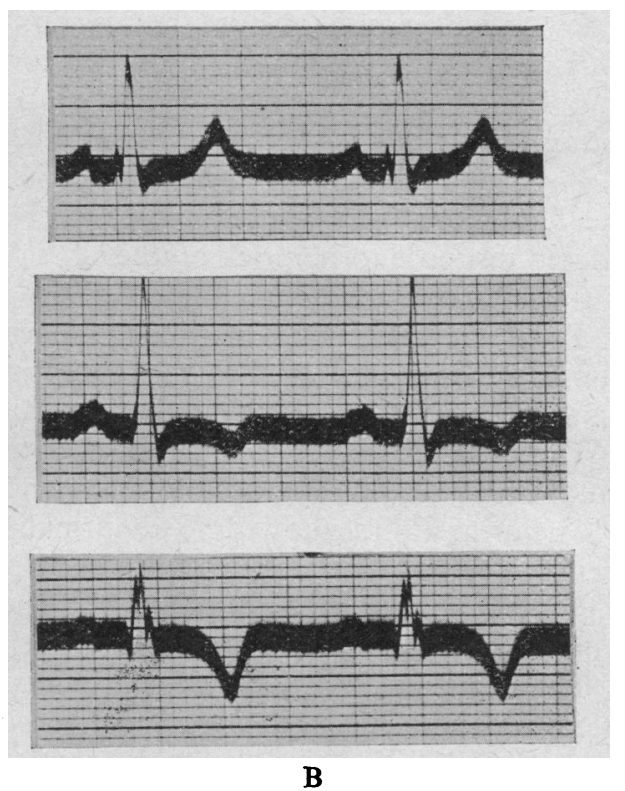

(B) One year later when

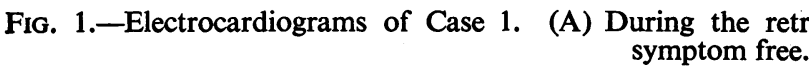

third week of treatment there was sudden onset of motor aphasia (the B.S.R. at this time was $3 \mathrm{~mm}$.). The total dosage of penicillin was seven million units over 30 days. Before discharge from hospital repeated blood cultures were sterile.

Three months later she reported herself as well, and the speech was normal except for an occasional hesitancy.

Comment. Presumably the retrobulbar neuritis was of embolic origin although examination at the time did not suggest any such dramatic event.

It is tempting to interpret the changes in the cardiogram (Fig. 1) as the result of a posterior infarction ; however, there is nothing to substantiate this clinically and serial cardiograms over a period of a year have shown little change in the contours, so that the aortic reflux alone is the likely cause of this ischæmic posterior coronary pattern.

The peculiar interest of the case is the unusual neurological presentation of subacute bacterial endocarditis and the lengthy latent period before general signs became apparent. At her first admission the retrobulbar neuritis was considered of the usual unknown ætiology there being no other embolic or toxæmic manifestation. Perhaps the onset of the disease, as evidenced by undue fatigue, dates from the birth of her child some sixteen months before frank symptoms; alternatively it may be suggested that the bacterial endocarditis dates only from 
the dental abscess which would entail a second pathology for the retrobulbar neuritis, a less attractive supposition.

Case 2. Subacute bacterial endocarditis with papillodema, mimicking intracranial tumour.

A married woman, aged 25, was admitted to hospital with a history of left hemiplegia of sudden onset. At the age of ten she had rheumatic fever which left in its train a heart murmur.

One week before admission there was severe epigastric pain followed two days later by numbness of the left side of the mouth, and the next morning she discovered her left side paralysed and anæsthetic. Eighteen months previously and coincident with the first pregnancy, she noted generalized vertical headaches; these were less evident after a miscarriage at ten weeks. Two months before admission, when she was again pregnant, she experienced troublesome right occipital headaches for two weeks, which recurred with the onset of the hemiplegia. One month ago there had been sudden pain in the left lower jaw with trismus lasting for a week. There had recently been some deterioration in vision.

Physical examination showed a left hemiplegia with maximum weakness in the left arm. The tendon reflexes were sluggish; there were a left Babinski, left hypoæsthesia, and a disordered response to pinprick on the left side. There was bilateral papillœdema, more marked on the left, with great engorgement of the retinal veins. There was no aphasia.

The temperature was normal; the heart was not apparently enlarged; rate, rhythm, and sounds were normal; at the apex there was a blowing systolic murmur. The blood pressure was $120 / 90$. She was eight weeks pregnant.

There was a tender swelling over the horizontal ramus of the left mandible without obvious dental cause, and radiographs of the mandible showed no abnormality.

The urine at first showed no abnormality but later there were occasional granular casts and a few red cells. The hæmoglobin was 70 per cent; the red cells $4,450,000$, and the white cells 16,000 with 84 per cent polymorphs. The blood sedimentation rate was $60 \mathrm{~mm}$. in the first hour. Repeated blood cultures were sterile.

The headache and papillœdema increased; vomiting later became frequent. A month after admission she suddenly complained of paræsthesiæ in the left hand with motor aphasia accompanied by an indescribable mental state, all of short duration. Ventriculography showed no abnormality. After three months of progressive deterioration the illness ended in bronchopneumonia. The temperature apart from an occasional rise to $99^{\circ}$ to $100^{\circ} \mathrm{F}$. at noon had shown little abnormal until the pre-terminal fever.

Autopsy. This revealed a small yellow area of necrosis in the posterior limb of the right internal capsule encroaching on the optic thalamus, a more recent infarct one inch in diameter in the right occipital lobe, and the most recent lesion two inches in diameter in the left parietal lobe.

The heart showed moderate dilatation of all its chambers. There was thickening and distortion of the anterior cusp of the mitral valve but there was no true stenosis. Mural endocarditis was present on the posterior wall of the left auricle. There were old infarctions in both kidneys and there was a single infarct in the spleen. The liver was enlarged and congested.

There were pleural adhesions over the right lung and early bronchopneumonia was present. The uterus contained a healthy male fotus of 4 to 5 months.

Comment. Here the antecedent period before gross embolic manifestation was probably eighteen months. At admission the picture was so dominated by the "choked discs" that the tentative diagnosis was intracranial tumour, in support of which were the progressive nature of the papillœdema and later vomiting. The possibility of bacterial endocarditis was entertained, but repeatedly negative blood cultures and the absence of fever, of splenomegaly, and of skin emboli obscured the true aetiology of the neurological findings. The presence of an old rheumatic valvular lesion was of paramount diagnostic significance. 


\section{Discussion}

Over an eight-year period there were 26 patients admitted to St. George's Hospital who showed unequivocal evidence of subacute bacterial endocarditis. Among these were 5 patients in whom note of ocular symptoms was made ; 3 showed hæmorrhage into the fundus oculi and the 2 with involvement of the optic nerve are here recorded. Krinsky and Merritt (1938) considered that 20 of their series of 100 cases of bacterial endocarditis showed a picture so predominantly neurological that the primary lesion was thought to lie in the central nervous system. They noted that 10 per cent of patients complained of visual disturbance at some stage of the disease, compared with headache the most common neurological symptom, which occurred in 24 per cent ; "choked discs" were observed in 8 per cent. They describe a slowly developing hemiplegia with mixed aphasia and left hypoalgesia in a left-handed male where progressive papillœdema appeared to support the diagnosis of tumour ; later fever, petechiæ, valvular involvement, and a positive blood culture established the true ætiology. In a further patient amblyopia had occurred some months before admission with hemiplegia, the result of endocarditis lenta.

As embolism is the essential feature of the symptomatology of subacute bacterial endocarditis and as death from cerebral embolism occurs in 23 per cent (Blumer, 1923), it is surprising that bizarre neurological and psychiatric complications are not more common. Kernohan et al. (1939) report that in every case of subacute bacterial endocarditis in which they examined the brain microscopically, widespread reactions associated with occluded arterioles or capillaries were found. The lesions were the result either of embolism, in which the endothelium of the intima surrounded the blood clot, or of thrombosis in situ, in which the initial lesion consisted of a hyaline change in the vessel wall progressing to partial occlusion of the lumen and here endothelial cells were present in the middle of hyaline thrombus. These latter changes they attribute to cocci or the local effect or their toxins.

Changes in the optic nerve are the result of occlusion in part of the blood supply, which gives rise to swelling of the nerve, lying for most of its course in the unyielding surroundings of the optic foramen. It is, therefore, a matter of the degree of occlusion and subsequent swelling whether retrobulbar neuritis with slight blurring of the disc outline or gross papillœdema with obstruction of the retinal veins occurs. Spread of intravascular clotting or repeated embolism is presumably the cause of the progressive nature of the papillodema, which seems to be characteristic. Theoretically there is no reason why the choked disc should not be unilateral, although it is probable that where repeated embolism has occurred in one optic nerve the other nerve is unlikely to remain unscathed.

The practical conclusion from the reported cases is that where rheumatic or congenital heart disease exists in the presence of neurological findings, particularly where these are of sudden onset, endocarditis lenta is a very real possibility; the absence of other contributory evidence is not exclusive of this diagnosis.

\section{SUMMARY}

Two cases of subacute bacterial endocarditis with early involvement of the optic nerve are described and the difficulty in diagnosis emphasized. Neurological presentation of the disease is not uncommon, and optic neuritis, even of a progressive nature, is not an incompatible finding.

I am indebted to Dr. Anthony Feiling and to Dr. C. B. Levick for permission to publish these cases.

\section{REFERENCES}

Blumer, G. (1923). Medicine, Baltimore, 2, 105.

Kernohan, J. W., Woltman, H. W., and Barnes, A. R. (1939). Arch. Neurol. Psychiat., 42, 789.

Kimmelstiel, P. (1928). Beitr. path. Anat. allg. Path., 79, 39.

Krinsky, C. M. and Merritt, H. H. (1938). New Eng. J. Med., 218, 563. 